\title{
Isolation, characterization and multi-lineage differentiation of stem cells from human exfoliated deciduous teeth
}

\author{
NAN ZHANG ${ }^{1,2}$, BAOXING CHEN $^{3}$, WEI WANG $^{1}, \mathrm{CHAO} \mathrm{CHEN}^{1}$, JIE KANG $^{3}$, \\ SAMUEL QINNAN DENG ${ }^{3}$, BIN ZHANG ${ }^{3,4}$, SHUWEI LIU ${ }^{2}$ and FABIN HAN ${ }^{1,4}$
}

\author{
${ }^{1}$ Centre for Stem Cells and Regenerative Medicine, Liaocheng People's Hospital/Affiliated Liaocheng Hospital, \\ Taishan Medical University, Liaocheng, Shandong 252000; ${ }^{2}$ Shandong Provincial Key Laboratory of Mental Disorders, \\ Research Center for Sectional and Imaging Anatomy, Shandong University School of Medicine, Jinan, Shandong 250012; \\ ${ }^{3}$ Department of Stomatology, ${ }^{4}$ Shandong Provincial Key Laboratory of Oral-facial Medical Biology, \\ Liaocheng People's Hospital/Affiliated Liaocheng Hospital, Taishan Medical University, \\ Liaocheng, Shandong 252000, P.R. China
}

Received February 4, 2015; Accepted March 2, 2016

DOI: $10.3892 / \mathrm{mmr} .2016 .5214$

\begin{abstract}
The aim of the present study was to isolate stem cells from human exfoliated deciduous teeth (SHEDs) and identify their phenotypes and multi-lineage differentiation potential. Three SHED cell strains were successfully isolated from three exfoliated deciduous teeth from different human subjects using the outgrowth method. Flow cytometric analysis indicated that SHEDs displayed high expression of the mesenchymal cell markers CD73 and CD90 but low expression of the hematopoietic stem cell marker CD34. PCR analysis illustrated that SHEDs expressed the mesenchymal stem cell markers CD44, CD73 and CD90, the osteoblast markers Alpl, Runx2, CBFA1 and collagen I, the cartilage cell markers Col10a1 and Acan, the adipose cell markers PPAR $\gamma 2$ and LPL, and the neuronal stem cell marker Nestin. In vitro induction experiments demonstrated the potential of the SHEDs for osteogenic, adipogenic and neurogenic differentiation. These SHED cells may be useful for further stem cell research and future therapeutic applications.
\end{abstract}

\section{Introduction}

Mesenchymal stem cells (MSCs) are multipotent stromal cells with the capability to differentiate into several cell types (1). MSCs have been isolated from various sources, including bone

Correspondence to: Professor Fabin Han, Centre for Stem Cells and Regenerative Medicine, Liaocheng People's Hospital/Affiliated Liaocheng Hospital, Taishan Medical University, 67 Dongchang West Road, Liaocheng, Shandong 252000, P.R. China E-mail: hanfabin2@gmail.com

Key words: dental pulp stem cell, stem cells from human exfoliated deciduous teeth, multiple-lineage differentiation, mesenchymal stem cells marrow, umbilical cord blood, muscle and adipose tissues. These cells have been shown to be able to differentiate into chondrocytes, adipocytes, myoblasts and osteoblasts in vitro, and are useful candidates for cell replacement therapy (2-4).

Dental stem cells are a particular type of MSCs and have been isolated from dental pulp, periodontal ligament, apical papilla and dental follicle. Each of these sources yields a different type of dental stem cell (5-8). Dental pulp stem cells (DPSCs), including exfoliated deciduous teeth cells (SHEDs), have the capacity for self-renewal and multi-lineage differentiation with the ability to differentiate into osteoblasts, hepatocytes, adipocytes, neural cells, chondrocytes, myocytes and odontoblasts (6,9-19). Dental stem cells express specific markers that are only expressd by MSCs and embryonic stem cells, including STRO-1, CD106, OCT4 and NANOG $(5-8,20,21)$.

Compared with other dental pulp stem cells, SHEDs have certain advantages: First, SHEDs exhibit a greater proliferative rate than other types of dental stem cell $(6,15,22)$; furthermore, SHEDs have been shown to exhibit a high capacity for bone/dentin formation in single colony-derived SHED clones when injected to immunodeficient mice (6).

However, SHEDs have remained to be fully characterized. Therefore, the present study was performed to examine the proliferative abilities, surface marker and specific gene expression as well as the multi-lineage differentiation ability of SHEDs. These cells may represent a valuable resource for tissue engineering and cell replacement therapy.

\section{Materials and methods}

Subjects and sample collection. Normal human deciduous incisors were collected from 6- to 8-year-old individuals at the dental clinic of Liaocheng People's Hospital with strict adherence to the guidelines approved by the Ethics Committee of Liaocheng People's Hospital (Liaocheng, China). Consent of the guardians of the individuals was obtained prior to sample extraction. Furthermore, each subject was examined to 
exclude systemic and oral infections, and only samples from disease-free subjects were used in the present study.

Cell culture and isolation. SHEDs were isolated and cultured according to the guidelines from established protocols with certain adjustments (23). Under aseptic conditions, the dental pulp cavity of the crown was opened using drills. The pulp was extracted with a broach, immediately placed in Dulbecco's modified Eagle's medium (DMEM)/F12 (Gibco; Thermo Fisher Scientific, Inc., Waltham, MA, USA) and transported to the laboratory. In the sterile cell culture hood, the pulp was washed three times with phosphate-buffered saline (PBS). The pulp tissue was then cut into small pieces $(\leq 0.5 \mathrm{~mm})$ in $10-\mathrm{cm}$ culture dishes. Sterile coverslips were used to cover the tissue blocks to keep them in place. The cells were cultured in maintenance medium comprising DMEM (Gibco) supplemented 10\% fetal bovine serum (Gibco), $100 \mathrm{U} / \mathrm{ml}$ penicillin (Gibco) and $100 \mathrm{U} / \mathrm{ml}$ streptomycin (Gibco) at $37^{\circ} \mathrm{C}$ in a humidified atmosphere with $5 \% \mathrm{CO}_{2}$. The culture medium was replaced every three days. Upon reaching $90 \%$ confluence, the cells were digested with TrypLE (Gibco) and passaged. Cells at passages 3-5 were used in the subsequent experiments.

Flow cytometry. The phenotypic characteristics of SHEDs were assessed by flow cytometry. Cells in the logarithmic growth phase were trypsinized, collected and washed twice with PBS. The cell concentration was adjusted to $1 \times 10^{7}$ cells $/ \mathrm{ml}$ and $100 \mu \mathrm{l}$ of the suspension was transferred into a fresh Eppendorf tube. Cells were blocked with $50 \mu 1$ normal goat serum (Gibco) for $15-20 \mathrm{~min}$ at room temperature. The cells were incubated with mouse anti-human fluorescein isothiocyanate-labeled monoclonal anti-CD90 (dilution, 1:50; cat. no. 555595), mouse anti-human phyeoerythrin (PE)-labeled monoclonal anti-CD73 (dilution, 1:50; cat. no. 561014) and mouse anti-human PE-labeled monoclonal anti-CD34 (dilution, 1:50; cat. no. 348057) (all purchased from BD Biosciences, Franklin Lakes, NJ, USA), and kept at $4{ }^{\circ} \mathrm{C}$ for $20 \mathrm{~min}$. Excess antibody was removed by washing twice with PBS. Finally, $500 \mu$ l fixative solution was added. Cells were analyzed using a BD FACSCalibur (BD Biosciences) and quantification was performed using Cell Quest software (version 3.3; BD Biosciences). FITC- or PE-labeled immunoglobulin G-stained cells were used as negative controls.

RNA isolation and polymerase chain reaction (PCR) analysis. Total RNA was obtained from $1 \times 10^{7}$ cells using TRIzol Reagent (Invitrogen; Thermo Fisher Scientific, Inc.). The residual DNA was removed with DNase I (Invitrogen). The activity of DNase I was inhibited by addition of $2.5 \mathrm{mM}$ ethylene diamine tetraacetic acid (Sigma-Aldrich, St. Louis, MO, USA) and incubation at $65^{\circ} \mathrm{C}$ for $10 \mathrm{~min}$. The quantity of total RNA was determined using SuperScript III Reverse Transcriptase (Invitrogen) according to the manufacturer's instructions. One microgram of total RNA (DNase I-treated) was used as a template to synthesize first-strand complementary DNA using SuperScript ${ }^{\circledR}$ III Reverse Transcriptase (Invitrogen). Primers listed in Table I were designed according to the cDNA sequences from GenBank (http://www.ncbi.nlm.nih. gov/genbank/). The synthesized cDNA was then subjected to PCR amplification. For real-time PCR, the following thermocycling conditions were used: 34 cycles of denaturation at $95^{\circ} \mathrm{C}$ for $30 \mathrm{sec}$, primer annealing at $60^{\circ} \mathrm{C}$ for $20 \mathrm{sec}$ and extension at $72^{\circ} \mathrm{C}$ for $30 \mathrm{sec}$. The PCR products were separated by electrophoresis in $1.5 \%$ agarose gels stained with ethidium bromide (Sigma-Aldrich) and visualized using a Bio-Rad ChemiDoc MP Imaging System (Bio-Rad Laboratories, Inc., Hercules, CA, USA).

Reverse-transcription quantitative (RT-q)PCR analysis was performed with SYBR Green PCR Master Mix (Applied Biosystems, Thermo Fisher Scientific, Inc.) on an ABI 7500 Fast Dx Real-Time PCR Instrument (Thermo Fisher Scientific, Inc.). Primers used were identical to those used for real-time PCR (Table I). Reaction conditions were as follows: Initial denaturation for $2 \mathrm{~min}$ at $50^{\circ} \mathrm{C}$ and $10 \mathrm{~min}$ at $95^{\circ} \mathrm{C}$, followed by 40 cycles of $15 \mathrm{sec}$ at $95^{\circ} \mathrm{C}$ and $1 \mathrm{~min}$ at $60^{\circ} \mathrm{C}$. Three independent experiments were performed in triplicate to confirm the reproducibility of the results. GAPDH was used as internal control. Relative expression levels were calculated using the $2^{-\triangle \triangle C q}$ method and values were presented as the mean expression level \pm standard deviation (SD) (24).

Osteogenic differentiation and Alizarin Red S staining. For osteogenic differentiation, cells were seeded in a six-well plate at a density of $2 \times 10^{4}$ cells $/ \mathrm{cm}^{2}$ and cultured in maintenance medium. When the cell monolayer reached $70 \%$ confluence, the medium was replaced with osteogenic differentiation medium [maintenance medium, $100 \mathrm{nmol} / 1$ dexamesone, $10 \mathrm{mM}$ $\beta$-glycerol phosphate, $50 \mu \mathrm{M}$ L-ascorbic acid 2-phosphate and $50 \mathrm{nM}$ vitamin D3 (all from Sigma-Aldrich)], followed by incubation for two weeks with the culture medium replaced twice a week. If the Alizarin Red S staining was not satisfactory, the cultures were cultivated for another two weeks. The control cells were kept in normal maintenance medium for the duration.

Alizarin Red S staining was performed once calcified nodules were observed at two or four weeks of induction. The medium was removed and the cells were fixed with $4 \%$ paraformaldehyde (m/v; Sigma-Aldrich). The plates were rinsed three times with $1 \mathrm{X}$ PBS and stained with $40 \mathrm{mM}$ Alizarin Red S (pH 4.2; Sigma-Aldrich) for 5-10 min at room temperature. Excess dye was removed in case of over-staining by washing three times with $1 \mathrm{X}$ PBS. Cells were observed and images were captured using an inverted fluorescence microscope (Nikon Ti-E; Nikon Corporation, Tokyo, Japan).

Adipogenic differentiation and Oil Red $O$ staining. For adipogenic differentiation, cells were seeded into six-well plates. When the cells reached $70 \%$ confluence, the medium was changed to adipogenic differentiation medium [maintenance medium supplemented with $1 \times 10^{6} \mathrm{~mol} / \mathrm{l}$ dexamesone, $10 \mu \mathrm{g} / \mathrm{ml}$ insulin, $0.5 \mathrm{mmol} / 13$-isobutyl-1-methylxanthine and $60 \mu \mathrm{mol} / 1$ indomethacin (all from Sigma-Aldrich)]. The medium was replaced twice a week for two weeks.

Oil Red O staining was performed after adipogenic induction. The medium was removed and the cells were fixed with $4 \%(\mathrm{~m} / \mathrm{v})$ paraformaldehyde. Oil Red O stock solution was prepared by dissolving $0.5 \mathrm{~g}$ Oil Red O (Sigma-Aldrich) in isopropanol, which was diluted with deionized water at a 3:2 ratio, followed by filtration using filter paper. Cells were stained 
Table I. Oligonucleotide primer sequences utilized for polymerase chain reaction analysis.

\begin{tabular}{|c|c|c|c|}
\hline Target cDNA & Primer sequence $\left(5^{\prime}-3^{\prime}\right)$ & Product size (bp) & GenBank ID \\
\hline \multirow[t]{2}{*}{ CD73 } & F:CTGCCTCTGTCCTCTTTCTT & & \\
\hline & R: TATTTTCTGACCACCCACTCA & 311 & NM_002526 \\
\hline \multirow[t]{2}{*}{ CD44 } & F: GGCTCACTCAAGCTCTTTAACT & & \\
\hline & R: TAGACCTCCCTTATTTCTATCGT & 283 & NM_000610 \\
\hline \multirow[t]{2}{*}{ CD90 } & F: GGGTTGGAGAAGGAGGTAAAG & & \\
\hline & R: CGCAGAAGTCCCTGAGAAG & 345 & NM_006288 \\
\hline \multirow[t]{2}{*}{ Alpl } & F:CACTCACTCCAAGACCACC & & \\
\hline & R: GTTTTGTGTTCCCTTTTAACCA & 216 & NM_000478 \\
\hline \multirow[t]{2}{*}{ Runx2 } & F:GCTTTACCATTCTTAGGTTTCTG & & \\
\hline & R: TACAATACAAATAGTCCCTTTGAA & 199 & NM_001024630 \\
\hline \multirow[t]{2}{*}{ CollagenI } & F:CCCTGGAAAGAATGGAGATGAT & & \\
\hline & R: ACTGAAACCTCTGTGTCCCTTCA & 138 & NM_000088 \\
\hline \multirow[t]{2}{*}{ Col10a1 } & F: TTTCAAAATTCGACTAGAAGTGG & & \\
\hline & R: CTTGAAAGAATGGTTGAGAACAG & 217 & NM_000493 \\
\hline \multirow[t]{2}{*}{ Acan } & F: CAGCTGAATGTATTGGATGAGAA & & \\
\hline & R: GGGGAGGGGAGAAGGTTG & 286 & NM_013227 \\
\hline \multirow[t]{2}{*}{$\operatorname{PPAR} \gamma 2$} & F: AGGAGCAGAGCAAAGAGGT & & \\
\hline & R: TTGGTCGTTCAAGTCAAGAT & 131 & NM_015869 \\
\hline \multirow[t]{2}{*}{ LPL } & F: TACACCAAACTGGTGGGACA & & \\
\hline & R: TGGATCGAGGCCAGTAATTC & 174 & NM_000237 \\
\hline \multirow[t]{2}{*}{ Nestin } & F: CAGGAGAAACAGGGCCTACA & & \\
\hline & R: TGGGAGCAAAGATCCAAGAC & 242 & NM_006617 \\
\hline \multirow[t]{2}{*}{ TUJ1 } & F: CCTTCATCGGGAACAGCACG & & \\
\hline & R: ACTCCTCCTCGTCGTCTTCGTA & 233 & NM_006086 \\
\hline
\end{tabular}

F, forward; R, reverse; cDNA, complementary DNA.

for $10 \mathrm{~min}$ at room temperature and excess dye was subsequently removed with $75 \%$ ethanol. Stained cells were observed under an inverted fluorescence microscope (Nikon Ti-E).

Chondrogenic differentiation and Alcian Blue staining. Cells at $70 \%$ confluence were induced in chondrogenic differentiation medium [maintenance medium supplemented with $100 \mathrm{ng} / \mathrm{ml}$ transforming growth factor (TGF)- $\beta 3$, $50 \mu \mathrm{g} / \mathrm{ml}$ ascorbic acid-2-phosphate, and $10 \mu \mathrm{g} / \mathrm{ml}$ insulin (all from Sigma-Aldrich)]. Medium was replaced every three or four days over three weeks.

For Alcian Blue staining, the culture medium was removed and cells were washed once with 1X PBS. Cells were then fixed with $4 \%$ paraformaldehyde for $20 \mathrm{~min}$, incubated in $1 \%$ Alcian Blue staining solution ( $\mathrm{pH}$ 2.5; Sigma-Aldrich) for $20 \mathrm{~min}$ at room temperature, washed three times with double distilled $\mathrm{H}_{2} \mathrm{O}$ and observed under an inverted fluorescence microscope (Nikon Ti-E).

Neurogenic differentiation and immunofluorescence analysis. For neurogenic differentiation, SHEDs at passages 3-7 were seeded into a six-well plate at $2 \times 10^{4}$ cells $/ \mathrm{cm}^{2}$. The induction process comprised two stages lasting a total of two weeks. At the first stage which lasted four days, the induction medium contained neurobasal medium containing $0.5 \%$ B27 supplement (both from Invitrogen), a cocktail of $200 \mathrm{ng} / \mathrm{ml}$ Sonic hedgehog, $100 \mathrm{ng} / \mathrm{ml}$ fibroblast growth factor 8 (both from ImmunoTools $\mathrm{GmbH}$, Friesoythe, Germany) and $50 \mathrm{ng} / \mathrm{ml}$ basic fibroblast growth factor (Sigma-Aldrich). At the second stage, the induction medium contained neurobasal media supplemented with $0.5 \% \mathrm{~B} 27$ and $10 \mathrm{ng} / \mathrm{ml}$ brain derived neurotrophic factor (ImmunoTools $\mathrm{GmbH}$ ) for the next 10 days. The induction medium was replaced every three to four days.

For immunofluorescence analysis, SHEDs were fixed with $4 \%$ paraformaldehyde for $1 \mathrm{~h}$ at day 14 after induction, washed with $1 \mathrm{X}$ PBS and blocked in $1 \%$ normal goat serum (Sigma-Aldrich) for $1 \mathrm{~h}$. The cells were then incubated with rabbit anti-human glial fibrillary acidic protein polyclonal antibody (GFAP; dilution, 1:500; cat. no. Z0334; Dako, Glostrup, Denmark) or mouse anti-human neuron specific class III $\beta$-tubulin monoclonal antibody (TUJ1; dilution, 1:500 dilution; cat. no. T8660; Sigma-Aldrich) at $4^{\circ} \mathrm{C}$ overnight. After washing three times with PBS, the cells were incubated with the following secondary antibodies for $2 \mathrm{~h}$ at room temperature in the dark: Cy 3-conjugated AffiniPure donkey anti-rabbit IgG polyclonal antibody (dilution, 1:300; cat. no. 711-165-152; Jackson Immuno Research Labs, West Grove, PA, USA) or Alexa Fluor 488 AffiniPure Goat Anti-Mouse IgG polyclonal 

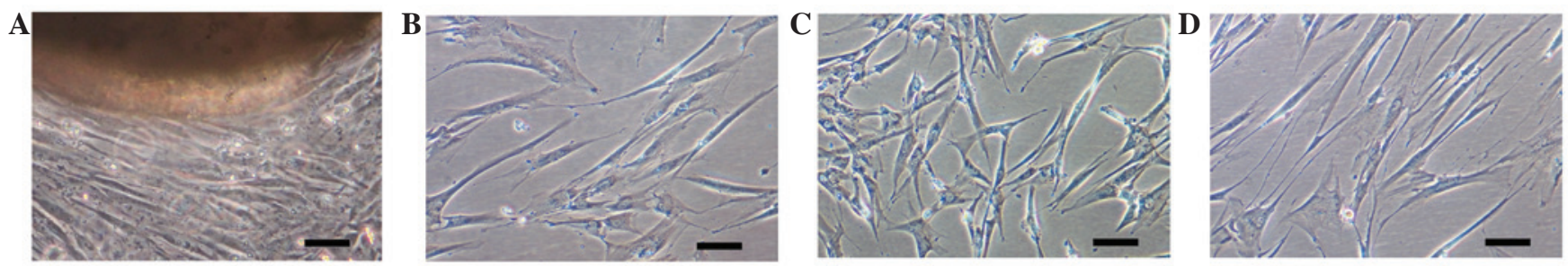

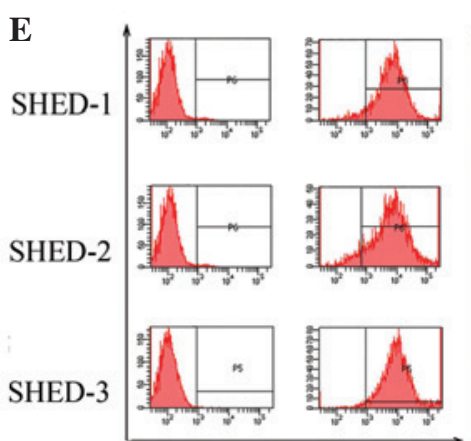

CD90

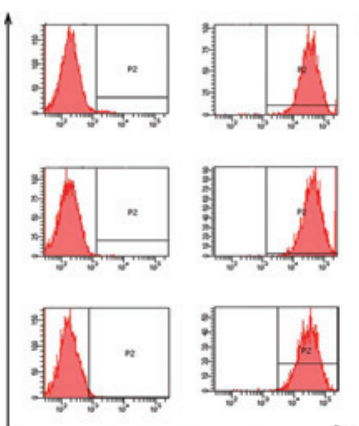

CD73

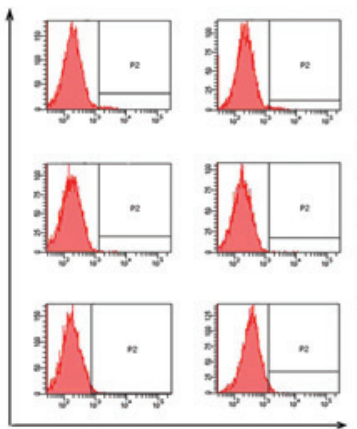

$\mathrm{CD} 34$

Percentage of positive cells

\begin{tabular}{llll}
\hline & CD90 & CD73 & CD34 \\
\hline SHED-1 & $90.92 \pm 1.65$ & $99.68 \pm 3.35$ & $1.62 \pm 0.21$ \\
SHED-2 & $85.80 \pm 3.31$ & $99.96 \pm 1.52$ & $0.29 \pm 0.05$ \\
SHED-3 & $91.48 \pm 2.44$ & $99.58 \pm 2.32$ & $1.21 \pm 0.09$
\end{tabular}

Figure 1. Isolation, morphological observation and flow cytometric analysis of stem cells from pulp tissue of human deciduous teeth. (A) Outgrowth of stem cells from dental pulp tissue of human exfoliated deciduous teeth. (B-D) Phase-contrast images showing the fibroblast-like morphology of the in vitro expanded SHEDs from three different patients (scale bar, $100 \mu \mathrm{m}$ ). (E) Flow cytometric analysis of the expression of mesenchymal stem cell markers CD73, CD90 and the hematopoietic marker CD34 on SHEDs. SHEDs, stem cells from human exfoliated deciduous teeth.

antibody (dilution, 1:300; cat. no. 115-545-146; Jackson Immuno Research Labs) Nuclei were stained with Hoechst 33258 (1:10,000 dilution; Santa Cruz Biotechnology, Inc., Dallas, TX, USA). After washing, the cells were examined under an inverted fluorescence microscope (Nikon Ti-E).

Statistical analysis. Statistical analyses were performed using SPSS version 11.0 (SPSS Inc., Chicago, IL, USA) and GraphPad Prism version 6 (GraphPad Software, Inc., La Jolla, CA, USA). Values are expressed as the mean \pm SD and images are representative of three independent experiments. Student's $\mathrm{t}$-test was used for statistical analysis. $\mathrm{P}<0.05$ was considered to indicate a statistically significant difference between values.

\section{Results}

Isolation and cultivation of dental pulp stem cells obtained from deciduous teeth. SHEDs were observed to grow out from the obtained dental pulp tissue clumps within 2-3 weeks of culture (Fig. 1A). Most cells had a typical fibroblast-like appearance. A small percentage of cells were polygonal, spindle shaped or oval shaped. Each cell had 1-2 projections (Fig. 1B-D). After passage, the cells were attached to the bottom of the culture flask within $2 \mathrm{~h}$ and reached $90 \%$ confluence within $\sim 1$ week. The SHEDs were cultured for 20 passages without any observed decreases of the cell growth rate.

Characterization of SHEDs. The isolated SHEDs were analyzed by flow cytometry to determine the expression of cell surface markers. The analysis indicated that the SHEDs

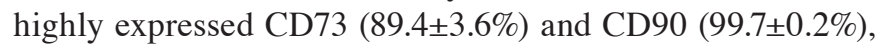
while not expressing the hematopoietic stem cell marker CD34 $(1.0 \pm 0.6 \%)$ (Fig. 1E).

The expression of marker genes in the SHEDs was also determined by reverse transcription-PCR. It was revealed that the SHEDs not only expressed the mesenchymal stem cell marker genes as CD73, CD90 and CD44 (Fig. 2A), but also expressed genes characteristic for osteoblasts, adipocytes, chondroblasts and neurocytes. Specifically, the SHEDs expressed Alpl, Runx2, CBFA1 and CollagenI as osteoblastic markers (Fig. 2B). Col10a1 and Acan as chondroblast markers (Fig. 2C), the adipocyte marker genes PPAR $\gamma 2$ and LPL (Fig. 2D) as well as the neuronal stem cell marker Nestin (Fig. 2E). The diversity of markers expressed confirmed the multi-lineage differentiation ability of the SHEDs.

Osteogenic differentiation of SHEDs. To test the osteogenic differentiation ability of the SHEDs, the cells were cultured in osteogenic induction medium for two weeks. Alizarin Red S staining showed that the SHEDs formed a small number of calcified nodules (Fig. 3A and B). After the osteogenic induction process was performed for a further two weeks, a large number of calcified nodules was observed (Fig. 3C and D). RT-qPCR analysis showed that after four weeks of induction, the expression of Alpl and Runx2 was increased by 2.17- and 2.13-fold of that in uninduced cells (Fig. 3E). These results indicated that SHEDs possess an osteogenetic capacity.

Adipogenic differentiation of SHEDs. After SHEDs were cultured in adipogenic medium, the growth of the cells was decreased. The morphology of certain cells changed from spindle-like to polygonal shapes within seven days, and cell hypertrophy was observed. Oil Red O staining revealed the presence of numerous lipid vacuoles after two weeks of induction (Fig. 4A-C). In addition, RT-qPCR showed that the expression of PPAR $\gamma 2$ and LPL was obviously increased in induced SHEDs compared to that in control cells; in particular, LPL increased to 31.7-fold of that of the control cells (Fig. 4D). This result indicated that SHEDs are able to differentiate into adipose cells under the induction conditions applied. 


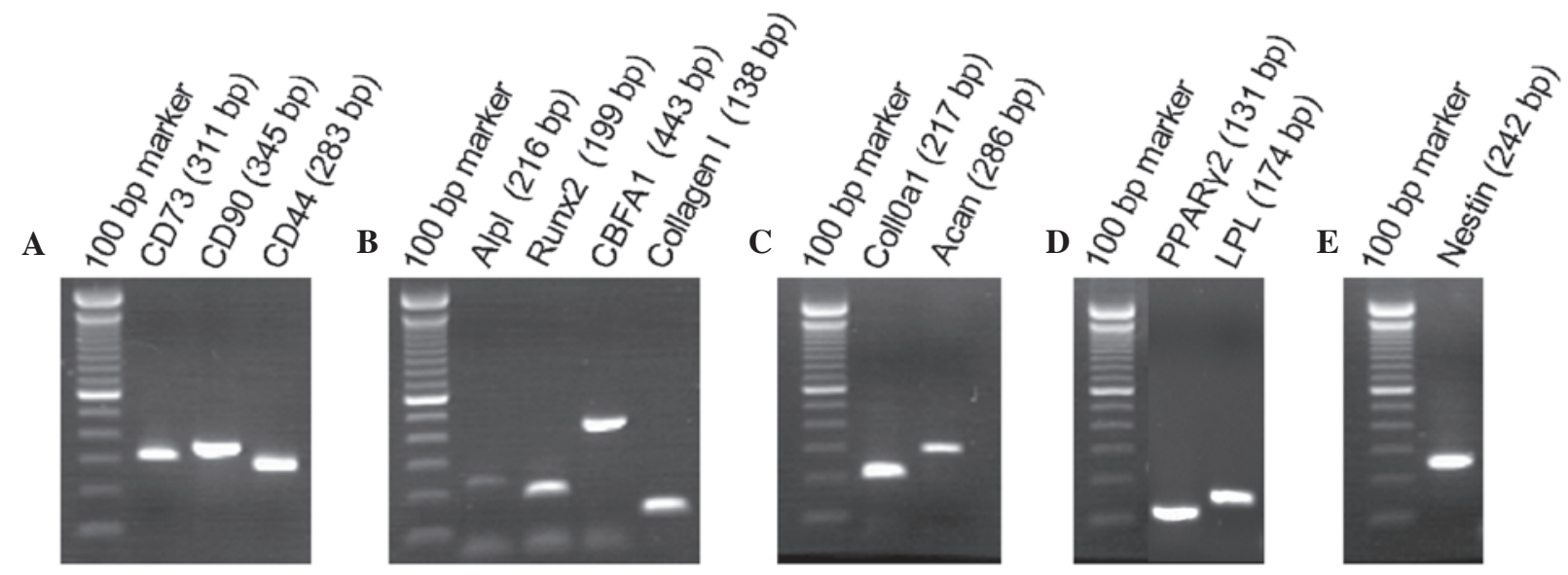

Figure 2. Polymerase chain reaction analysis of various genes expressed in SHEDs. Electrophoretic gels showing the expression of (A) stem cell marker genes CD44, CD73 and CD90, (B) osteoblast marker genes Alpl, Runx2, CBFA1 and Collagen I, (C) chondroblast marker genes Col10a1 and Acan, (D) adipocyte marker genes PPAR $\gamma 2$ and LPL, and (E) neural stem cells marker gene Nestin. SHEDs, stem cells from human exfoliated deciduous teeth.
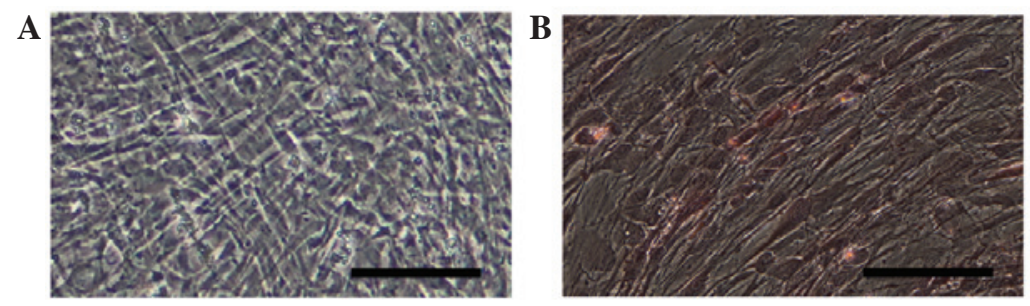

$\mathbf{E}$
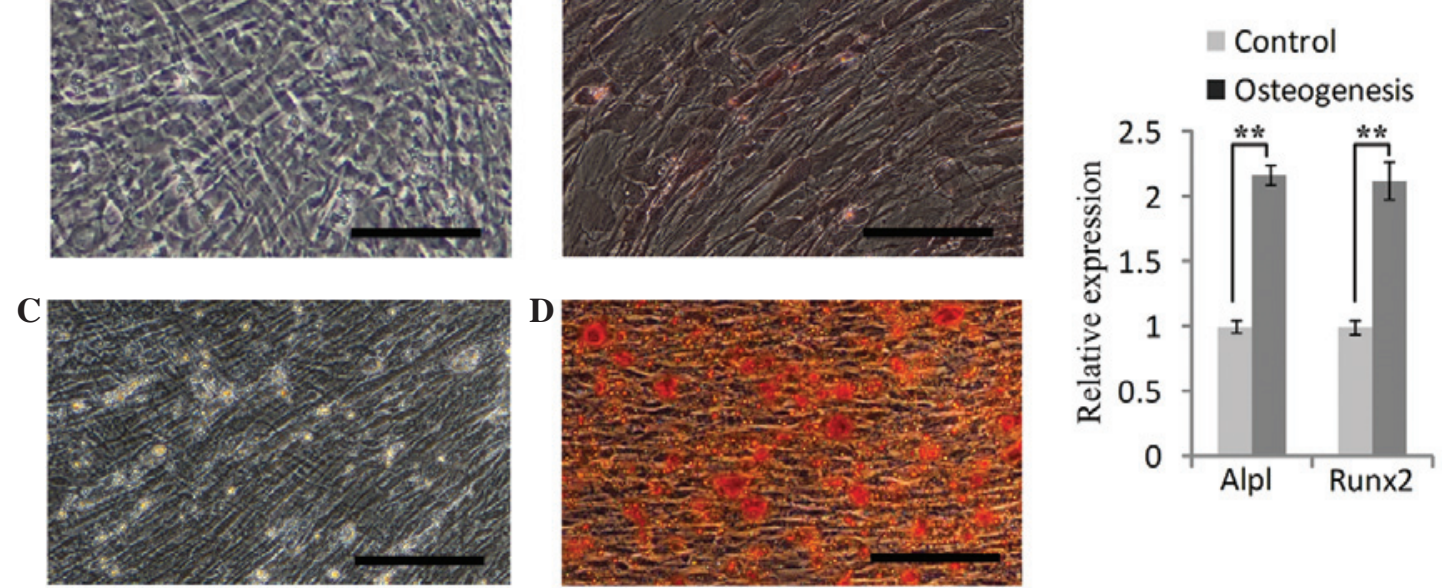

Figure 3. Osteogenic differentiation potential of SHEDs. Phase-contrast images showing (A and B) SHEDs subjected to osteogenic induction for two weeks. (C and D) SHEDs subjected to osteogenic induction for four weeks (scale bar, $100 \mu \mathrm{m}$ ). Cells on the right-hand panel were subjected to Alizarin Red S staining to detect calcium deposits. (E) mRNA expression levels of the osteogenic marker genes Alpl and Runx2 prior to and after osteogenic induction for four weeks as determined by quantitative polymerase chain reaction analysis. Values are expressed as the mean \pm standard deviation. ${ }^{* *} \mathrm{P}<0.01$. SHEDs, stem cells from human exfoliated deciduous teeth.
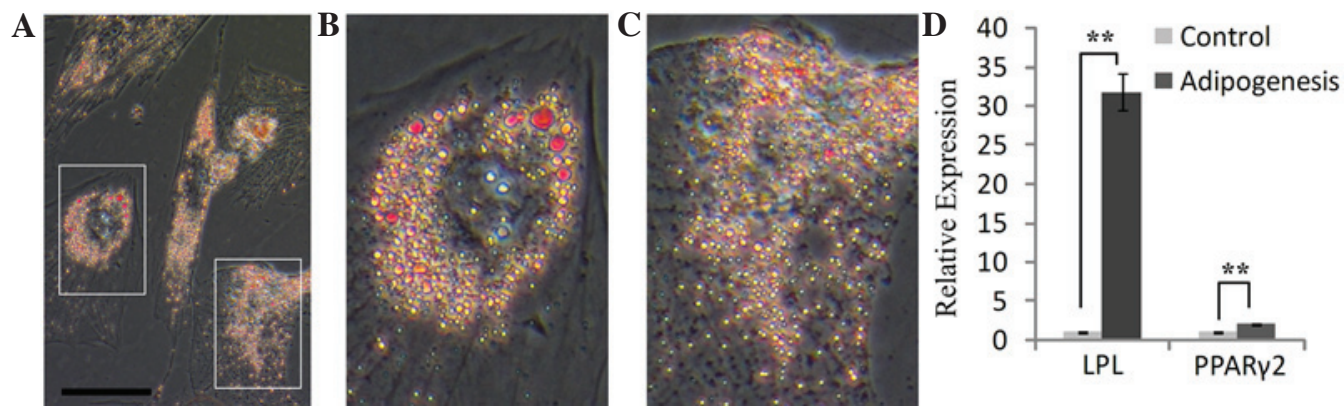

Figure 4. Adipogenic differentiation potential of SHEDs. (A) Oil Red O staining of SHEDs after two weeks of adipogenic induction (scale bar, $50 \mu \mathrm{m}$ ). (B and C) Magnified (x3) windows from A showing the lipid vacuoles inside SHEDs. (D) Comparison of LPL and PPAR $\gamma 2$ expression prior to and after adipogenic induction as detected by quantitative reverse-transcription polymerase chain reaction analysis. Values are expressed as the mean \pm standard deviation. ${ }^{*} \mathrm{P}<0.01$. SHEDs, stem cells from human exfoliated deciduous teeth.

Chondrogenic differentiation of SHEDs. To assess their chondrogenic differentiation capacity, SHEDs were cultured in induction medium containing TGF- $\beta 3$. Alcain blue was used to detect the extracellular matrix proteoglycan, and positive staining was observed after chondrogenic induction for three weeks (Fig. 5A). Furthermore, RT-qPCR was used to analyze 

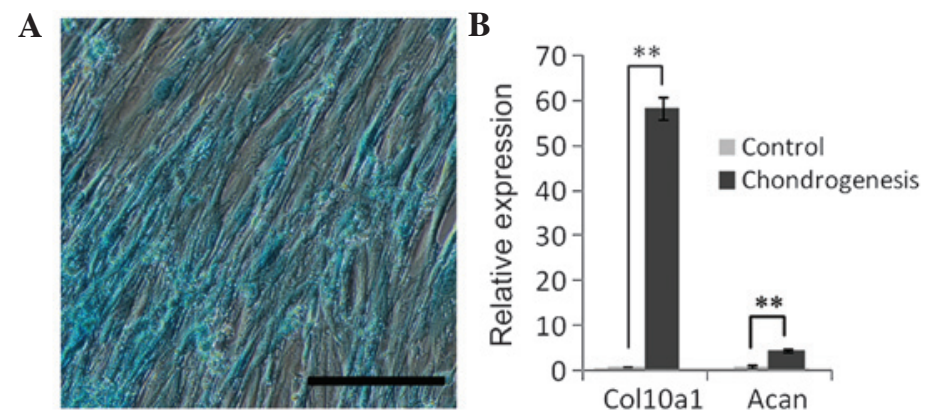

Figure 5. Chondrogenic differentiation potential of SHEDs. (A) Alcian Blue staining of SHEDs after three weeks of chondrogenic induction (scale bar, $100 \mu \mathrm{m}$ ). (B) Expression of Col10a1 and Acan prior to and after chondrogenic induction as detected by quantitative reverse-transcription polymerase chain reaction analysis. Values are expressed as the mean \pm standard deviation. ${ }^{* *} \mathrm{P}<0.01$. SHEDs, stem cells from human exfoliated deciduous teeth.
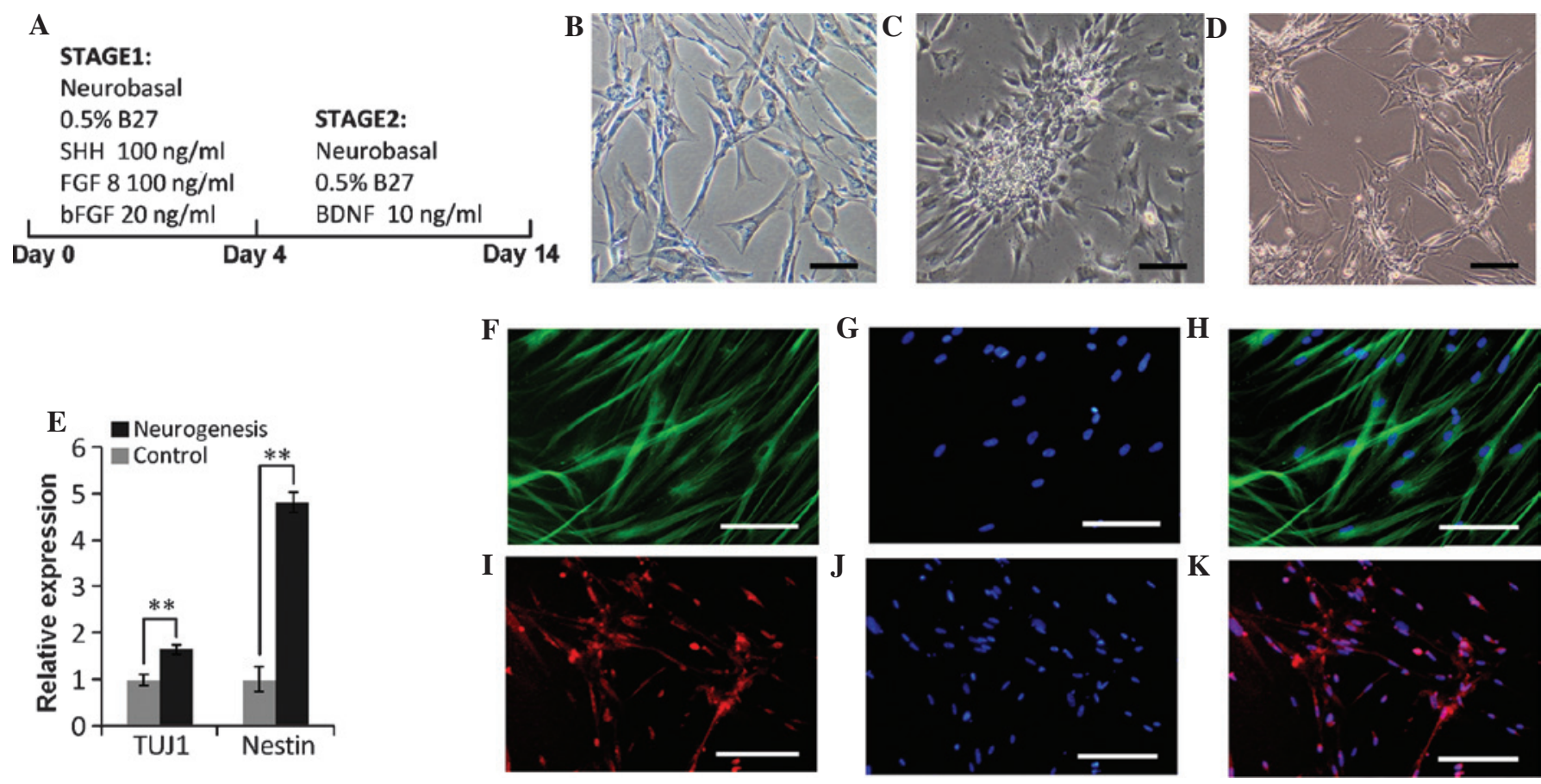

Figure 6. Neurogenic differentiation of SHEDs. (A) Neurogenic differentiation schedule of SHEDs over two weeks. (B-D) Cell morphology of SHEDs at days 0 , 4 and 14, respectively, after neurogenic induction. (E) mRNA expression of Nestin and TUJ1 prior to and after neurogenic induction as detected by quantitative reverse-transcription polymerase chain reaction analysis. Values are expressed as the mean \pm standard deviation. ${ }^{* *} \mathrm{P}<0.01$. (F-H) Immunofluorescence staining for the expression of neuronal marker TUJ1 in differentiated SHEDs. (F) TUJ1 (green); (G) Hoechst 33258 (blue); (H) Overlap of TUJ1 and Hoechst 33258. (I-K) Immunofluorescence staining for the expression of astrogial marker GFAP in SHEDs after neurogenic induction. (I) GFAP (red); (J) Hoechst 33258 (blue); (K) Overlap of GFAP and Hoechst 33258. Scale bar, $100 \mu \mathrm{m}$. SHEDs, stem cells from human exfoliated deciduous teeth.

the expression of Acan and Col10a1, revealing an upregulation by 4.7 - and 58.43 -fold, respectively, compared with that in the control group (Fig. 5B). These results indicated that SHEDs were able to differentiate into chondroblast cells.

Neuronal differentiation of SHEDs. Developmental studies showed that DPSCs originate from neuroectodermal tissue. Previous studies have indicated that DPSCs contain a subset of progenitor cells that can differentiate towards mature neurons under the appropriate conditions $(25,26)$. A two-stage protocol was used to induce the SHEDs to differentiate into neuronal cells (Fig. 6A). After the first stage, the cells formed rosette-shaped clusters and after the second stage, a percentage of cells exhibited a neuron-like appearance (Fig. 6B-D). RT-qPCR indicated that TUJ1 and Nestin were obviously upregulated by 1.67 - and 4.84 -fold, respectively, of that of undifferentiated control cells (Fig. 6E). In addition, immunofluorescence staining was performed for the neuron-specific markers TUJ1 and GFAP, revealing a high expression of TUJ1 (Fig. 6F-H) and GFAP (Fig. 6I-K) in these neuron-shaped cells. All of these results showed that SHEDs were be able to differentiate into neuron-like cells.

\section{Discussion}

Human DPSCs represent a novel type of stem cells featuring high proliferative potential, capacity for self-renewal and multi-lineage differentiation $(5,9,23)$. Among them, SHEDs were first isolated by Miura et al (6) in 2003 from dental pulp of exfoliated deciduous teeth. The proliferation rate and colony-forming ability of SHEDs was higher than that of stem cells from permanent teeth. Furthermore, it has been shown 
that in SHEDs, the expression of pluripotent markers, including OCT4, SOX2, NANOG and REX1, was higher ( $>2.0$ fold) compared with that in stem cells from permanent teeth (19). Owing to their higher proliferation rate and higher expression levels of pluripotent markers, SHEDs are considered to be a more immature form of stem cells than those obtained from permanent teeth.

There are two methods to isolate SHEDs from pulp tissue: Enzymatic dissociation of pulp tissue and outgrowth from tissue explants (27). Although enzyme digestion is considered to be the most common method used to acquire dental pulp stem cells (28-30), it has been reported that the outgrowth method can also be used to acquire multipotent stem cells $(31,32)$. In the present study, the outgrowth method was used to isolate the cells from pulp tissue, as only a small amount of pulp tissue is available from deciduous teeth and the method was easy and convenient.

The results of the present study showed that SHEDs expressed various markers of bone, adipose, cartilage and neural cells, probably due to the heterogeneous populations of stem cells. Pulp is composed of different cell types, including odontoblasts, vessels, nerves, firoblasts and multiple stem cells $(33,34)$. In the present study, a specific sub-type of SHEDs was examined. For use as a source for cell therapy, the heterogenous SHEDs are preferred, as they are enabled to cope with the various environmental cues after cell transplantation. However, in other cases, pre-selected cells [sorted using magnetic-activated cell sorting (MACS)] were shown to be more effective than heterogeneous stem cells. For example, human c-kit ${ }^{+} / \mathrm{CD} 34^{+} / \mathrm{CD} 45^{-}$DPSCs have been demonstrated to be a promising sub-population for bone-tissue engineering $(35,36)$.

The present study found that SHEDs shared multiple characteristics with mesenchymal stem cells. First, SHEDs were demonstrated to have a marked capacity to proliferate. The SHEDs were passaged once per week until passage 20 , with their growth rate remaining constant over this duration. Furthermore, SHEDs expressed mesenchymal stem cell markers. Flow cytometry results demonstrated that $>90 \%$ of SHEDs expressed CD73 and CD90, and RT-qPCR illustrated that SHEDs also expressed CD44. This was consistent with the findings of a previous study (37). Finally, SHEDs were found to have potential for multi-lineage differentiation, including osteogenic, adipogenic, chrongenic and neurogenic differentiation $(6,12-15,38)$.

The differentiation potential of stem cells is important when considering their potential to regenerate specific tissues, including bone, cartilage or adipose tissue. The present study demonstrated that SHEDs were able to differentiate into cells that form large lipid droplets, calcium salts, cartilage or neural-like tissue with the up-regulation of the corresponding marker genes. However, as not all of the SHEDs had multiple differentiation ability, pre-selection of a cell sub-population by MACS for engineering of different tissue types such as bone, cartilage, nerve and vessels may be a better choice.

The present study reported on the isolation, culture and characterization of SHEDs. An improved outgrowth from tissue explant method was developed to isolate the SHEDs. These cells expressed stem cell markers such as CD44, CD73 and CD90. In response to appropriate stimuli, the cells were able to differentiate into bone, adipose, cartilage and neural cells, as evidenced by the expression of the respective tissue-specific markers. The present study therefore further paved the road for the utilization of SHEDs for tissue engineering.

\section{Acknowledgements}

This work was supported by the research grants from Research Scholar Fund of Liaocheng People's Hospital of Shandong province (no. 2011LCYYF001) and the Special Fund for Post Doctoral Innovation Projects of Shandong Province (no. 201303025).

\section{References}

1. Caplan AI: Mesenchymal stem cells. J Orthop Res 9: 641-650, 1991.

2. Dimarino AM, Caplan AI and Bonfield TL: Mesenchymal stem cells in tissue repair. Front Immunol 4: 201, 2013.

3. Jiang Y, Jahagirdar BN, Reinhardt RL, Schwartz RE, Keene CD, Ortiz-Gonzalez XR, Reyes M, Lenvik T, Lund T, Blackstad M, et al: Pluripotency of mesenchymal stem cells derived from adult marrow. Nature 418: 41-49, 2002.

4. Jin HJ, Bae YK, Kim M, Kwon SJ, Jeon HB, Choi SJ, Kim SW, Yang YS, Oh W and Chang JW: Comparative analysis of human mesenchymal stem cells from bone marrow, adipose tissue, and umbilical cord blood as sources of cell therapy. Int J Mol Sci 14: 17986-18001, 2013.

5. Gronthos S, Mankani M, Brahim J, Robey PG and Shi S: Postnatal human dental pulp stem cells (DPSCs) in vitro and in vivo. Proc Natl Acad Sci USA 97: 13625-13630, 2000.

6. Miura M, Gronthos S, Zhao M, Lu B, Fisher LW, Robey PG and Shi S: SHED: Stem cells from human exfoliated deciduous teeth. Proc Natl Acad Sci USA 100: 5807-5812, 2003.

7. Morsczeck C, Götz W, Schierholz J, Zeilhofer F, Kühn U, Möhl C, Sippel C and Hoffmann KH: Isolation of precursor cells (PCs) from human dental follicle of wisdom teeth. Matrix Biol 24: 155-165, 2005.

8. Seo BM, Miura M, Gronthos S, Bartold PM, Batouli S, Brahim J, Young M, Robey PG, Wang CY and Shi S: Investigation of multipotent postnatal stem cells from human periodontal ligament. Lancet 364: 149-155, 2004.

9. Zhang W, Walboomers XF, Shi S, Fan M and Jansen JA: Multilineage differentiation potential of stem cells derived from human dental pulp after cryopreservation. Tissue Eng 12: 2813-2823, 2006.

10. Sonoyama W, Liu Y, Yamaza T, Tuan RS, Wang S, Shi S and Huang GT: Characterization of the apical papilla and its residing stem cells from human immature permanent teeth: A pilot study. J Endod 34: 166-171, 2008.

11. Morsczeck C, Völlner F, Saugspier M, Brandl C, Reichert TE, Driemel O and Schmalz G: Comparison of human dental follicle cells (DFCs) and stem cells from human exfoliated deciduous teeth (SHED) after neural differentiation in vitro. Clin Oral Investig 14: 433-440, 2010.

12. Ma L, Makino Y, Yamaza H, Akiyama K, Hoshino Y, Song G, Kukita T, Nonaka K, Shi S and Yamaza T: Cryopreserved dental pulp tissues of exfoliated deciduous teeth is a feasible stem cell resource for regenerative medicine. PLoS One 7: e51777, 2012

13. Nourbakhsh N, Soleimani M, Taghipour Z, Karbalaie K, Mousavi SB, Talebi A, Nadali F, Tanhaei S, Kiyani GA, Nematollahi M, et al: Induced in vitro differentiation of neural-like cells from human exfoliated deciduous teeth-derived stem cells. Int J Dev Biol 55: 189-195, 2011.

14. Eslaminejad MB, Vahabi S, Shariati $M$ and Nazarian $H$ : In vitro growth and characterization of stem cells from human dental pulp of deciduous versus permanent teeth. J Dent (Tehran) 7: 185-195, 2010.

15. Koyama N, Okubo Y, Nakao K and Bessho K: Evaluation of pluripotency in human dental pulp cells. J Oral Maxillofac. Surg 67: 501-506, 2009.

16. Lizier NF, Kerkis A, Gomes CM, Hebling J, Oliveira CF, Caplan AI and Kerkis I: Scaling-up of dental pulp stem cells isolated from multiple niches. PLoS One 7: e39885, 2012. 
17. Casagrande L, Demarco FF, Zhang Z, Araujo FB, Shi S and Nör JE: Dentin-derived BMP-2 and odontoblast differentiation. J Dent Res 89: 603-608, 2010.

18. Ishkitiev N, Yaegaki K, Calenic B, Nakahara T, Ishikawa H, Mitiev V and Haapasalo M: Deciduous and permanent denta pulp mesenchymal cells acquire hepatic morphologic and functional features in vitro. J Endod 36: 469-474, 2010.

19. Kerkis I, Kerkis A, Dozortsev D, Stukart-Parsons GC, Gomes Massironi SM, Pereira LV, Caplan AI and Cerruti HF: Isolation and characterization of a population of immature dental pulp stem cells expressing OCT-4 and other embryonic stem cell markers. Cells Tissues Organs 184: 105-116, 2006.

20. Ferro F, Spelat R, D'Aurizio F, Puppato E, Pandolfi M, Beltrami AP, Cesselli D, Falini G, Beltrami CA and Curcio F: Dental pulp stem cells differentiation reveals new insights in Oct4A dynamics. PLoS One 7: e41774, 2012.

21. Sonoyama W, Liu Y, Fang D, Yamaza T, Seo BM, Zhang C, Liu H, Gronthos S, Wang CY, Wang S, et al: Mesenchymal stem cell-mediated functional tooth regeneration in swine. PLoS One 1: e79, 2006.

22. Nakamura S, Yamada Y, Katagiri W, Sugito T, Ito K and Ueda M: Stem cell proliferation pathways comparison between human exfoliated deciduous teeth and dental pulp stem cells by gene expression profile from promising dental pulp. J Endod 35 $1536-1542,2009$.

23. Huang GT, Gronthos S and Shi S: Mesenchymal stem cells derived from dental tissues vs. those from other sources: Their biology and role in regenerative medicine. J Dent Res 88 792-806, 2009

24. Livak KJ and Schmittgen TD: Analysis of relative gene expression data using real-time quantitative PCR and the 2(-Delta Delta C(T)) Method. Methods 25: 402-408, 2001.

25. Pittenger MF, Mackay AM, Beck SC, Jaiswal RK, Douglas R, Mosca JD, Moorman MA, Simonetti DW, Craig S and Marshak DR: Multilineage potential of adult human mesenchymal stem cells. Science 284: 143-147, 1999.

26. Govindasamy V, Abdullah AN, Ronald VS, Musa S, Ab Aziz ZA, Zain RB, Totey S, Bhonde RR and Abu Kasim NH: Inherent differential propensity of dental pulp stem cells derived from human deciduous and permanent teeth. J Endod 36: 1504-1515, 2010.

27. Hilkens P, Gervois P, Fanton Y, Vanormelingen J, Martens W, Struys T, Politis C, Lambrichts I and Bronckaers A: Effect of isolation methodology on stem cell properties and multilineage differentiation potential of human dental pulp stem cells. Cell Tissue Res 353: 65-78, 2013.
28. Arora V, Arora P and Munshi AK: Banking stem cells from human exfoliated deciduous teeth (SHED): Saving for the future. J Clin Pediatr Dent 33: 289-294, 2009.

29. Gay IC, Chen S and MacDougall M: Isolation and characterization of multipotent human periodontal ligament stem cells. Orthod Craniofac Res 10: 149-160, 2007.

30. Nishino Y, Yamada Y, Ebisawa K, Nakamura S, Okabe K, Umemura E, Hara K and Ueda M: Stem cells from human exfoliated deciduous teeth (SHED) enhance wound healing and the possibility of novel cell therapy. Cytotherapy 13: 598-605, 2011.

31. Bakopoulou A, Leyhausen G, Volk J, Tsiftsoglou A, Garefis P, Koidis P and Geurtsen W: Assessment of the impact of two different isolation methods on the osteo/odontogenic differentiation potential of human dental stem cells derived from deciduous teeth. Calcif Tissue Int 88: 130-141, 2011.

32. Spath L, Rotilio V, Alessandrini M, Gambara G, De Angelis L, Mancini M, Mitsiadis TA, Vivarelli E, Naro F, Filippini A, et al: Explant-derived human dental pulp stem cells enhance differentiation and proliferation potentials. J Cell Mol Med 14: 1635-1644, 2010

33. Avery JK: Structural elements of the young normal human pulp. Oral Surg Oral Med Oral Pathol 32: 113-125, 1971.

34. Shi S and Gronthos S: Perivascular niche of postnatal mesenchymal stem cells in human bone marrow and dental pulp. J Bone Miner Res 18: 696-704, 2003.

35. Laino G, Carinci F, Graziano A, d'Aquino R, Lanza V, De Rosa A, Gombos F, Caruso F, Guida L, Rullo R, et al: In vitro bone production using stem cells derived from human dental pulp. J Craniofac Surg 17: 511-515, 2006.

36. Laino G, d'Aquino R, Graziano A, Lanza V, Carinci F, Naro F, Pirozzi G and Papaccio G: A new population of human adult dental pulp stem cells: A useful source of living autologous fibrous bone tissue (LAB). J Bone Miner Res 20: 1394-1402, 2005.

37. Vakhrushev IV, Antonov EN, Popova AV, Konstantinova EV, Karalkin PA, Kholodenko IV, Lupatov AY, Popov VK, Bagratashvili VN and Yarygin KN: Design of tissue engineering implants for bone tissue regeneration of the basis of new generation polylactoglycolide scaffolds and multipotent mesenchymal stem cells from human exfoliated deciduous teeth (SHED cells). Bull Exp Biol Med 153: 143-147, 2012.

38. Taghipour Z, Karbalaie K, Kiani A, Niapour A, Bahramian H, Nasr-Esfahani $\mathrm{MH}$ and Baharvand $\mathrm{H}$ : Transplantation of undifferentiated and induced human exfoliated deciduous teeth-derived stem cells promote functional recovery of rat spinal cord contusion injury model. Stem Cells Dev 21: 1794-1802, 2012. 